\title{
Configurações de um cenário territorial: o eixo Rio Doce/bairro São Tarcísio/ribeirinhos (Governador Valadares/MG)
}

\author{
Configurations of a territorial scenario: the rio Doce, São Tarcísio \\ Quarter and Riparians (Governador Valadares- $M G$ ) axis
}

\author{
Patrícia Falco Genovez* \\ José Bispo Ferreira Filho**
}

RESUMO

O bairro de São Tarcísio, próximo ao rio Doce - Governador Valadares, Brasil - é o cenário de um território factível onde uma porção específica de terra associa-se de modo vago (frouxo) com um solonatureza e a alguns traços humanos especiais marcados culturalmente. Na realidade, este ensaio lida com três dimensões ao mesmo tempo: o rio, o bairro e os seus moradores. Tendo presente um processo histórico, um 'clima' de sentimentos e algumas categorias como imaginário, representações, códigos sociais e identidade como os principais instrumentos, pode-se encontrar um caminho de se chegar ao de produção e reprodução simbólica deste processo de territorialização. 0 território é compreendido como o produto de uma cena de um território factível através da apropriação material e simbólica de um espaço. Esta apropriação vincula-se profundamente ao imaginário, à experiência, ao mítico, à vida cotidiana e códigos culturais.

Palavras-chave: Território. Bairro. Ribeirinhos. Rio Doce. Interdisciplinaridade.

\section{ABSTRACT}

The quarter of São Tarcísio near river Doce - Governador Valadares, Brazil - is a scenario of a feasible territory where a specific portion of land is loosely associated with a physical soil and some particular humans traits printed culturally. Actually, this essay deals with three dimensions at the same time: the River, the quarter and its inhabitants. Having in mind an historical process, a realm of feelings and some

\footnotetext{
* Professora do curso de História e do Mestrado em Gestão Integrada do Território (GIT/Univale). Pesquisadora do Observatório Interdisciplinar do Território/Univale. Doutora em História Moderna e Contemporânea (UFF).

** Professor do curso de Design/Univale. Mestre em Gestão Integrada do Território.
} 
categories like imaginary, representations, social codes and identity as the main tools one could get a way in order to reach the process of symbolic production and reproduction of this process of territorialization. The territory is understood as the product of a scene of feasible territory through the material and symbolic appropriation of a space. This appropriation is deeply linked to the imaginary, to experience, to the mythical, to the day-by-day life and cultural codes.

Keywords: Territory (Feasible Territory Scenario). Quarter (Burgh). Riparian. Rio Doce. Interdisciplinarity.

\section{Introdução}

A título de uma breve contextualização, o bairro São Tarcísio, localizado na parte central da cidade de Governador Valadares (MG), foi oficialmente criado na década de 1950 (Figura 1). Mas, antes disso, a região ribeirinha já era habitada, uma vez que possuía um pequeno porto de canoas e algumas casas próximas à atual Rua Prudente de Moraes (SIMAN, 1988, p.78). Enquanto bairro, o São Tarcísio pode ser, ordinariamente, definido através das mesmas características que permeiam outros territórios de igual escala, ou seja, trata-se de uma divisão territorial de uma cidade. $O$ espaço do São Tarcísio, assim, pode ser classificado com referências ao latim barrium ou mesmo do árabe barri (de fora, exterior, separado). Isso porque, em termos gerais, pode ser compreendido como uma das zonas principais em que se divide uma cidade, ou uma "porção de território nas proximidades de um núcleo urbano" (BARROS, 2002, p. 7). O bairro, então, estaria associado à idéia de separação, delimitação de um espaço físico que abriga uma população. Bairros como o São Tarcísio são considerados urbes "porque fazem parte da cidade". Um bairro pode ser caracterizado pelo sentimento de localidade existente nos seus moradores, e cuja formação depende não apenas da posição geográfica, mas, também, do intercâmbio entre as famílias e as pessoas no espaço físico (BARROS, 2002, p.12). 


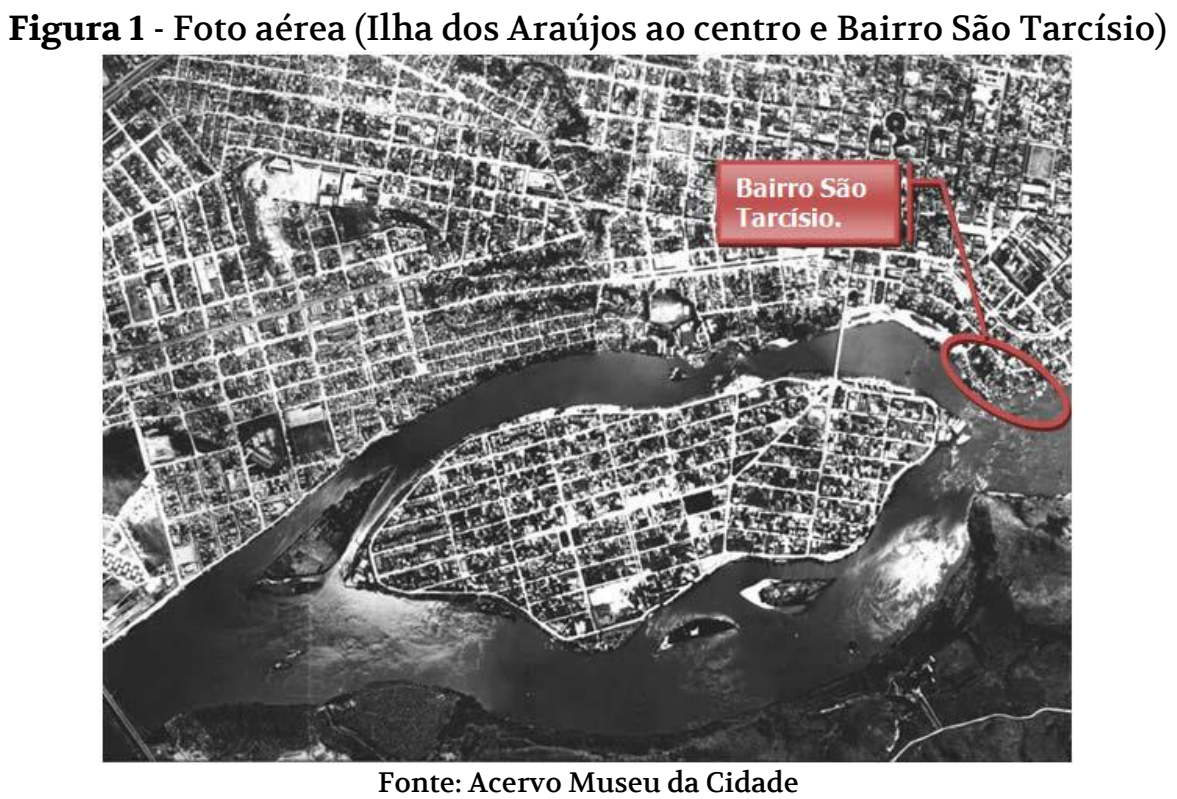

É neste processo histórico, composto por uma esfera de sentimentos que pretendemos, apoiados na Geografia Cultural, desenvolver este trabalho. Consideraremos categorias, tais como, imaginário, representações, códigos e identidades, como de suma importância para compreendermos a possível existência de um processo de produção simbólica. Para tanto, a cidade de Governador Valadares se oferece, numa escala maior, não apenas como referência para buscarmos compreensão dos aspectos presentes no bairro, mas, como cenário que nos auxiliaria na compreensão de influências tanto históricas e sociais, como culturais, no que diz respeito ao convívio com o rio Doce e a alguns comportamentos/códigos que fariam parte de uma possível dinâmica entre o micro e o macro.

Assim, considerando inicialmente a cidade como uma escala maior, temos: uma cidade considerada de porte médio, com seus 276 mil habitantes (IBGE, 2010), emancipada em 1938 e que, a partir de 1940 e 1950, registrou notável crescimento econômico, com a exploração da mica e da madeira da região. Junto com o crescimento populacional, que saltou de 5.734 habitantes para 20.357,em 1950, a cidade, então, recebeu uma nova demarcação: surgiram os bairros para abrigar os trabalhadores da indústria da madeira. É neste momento que a cidade e região tornam-se alvo de programas sanitaristas a cargo do Serviço Especial de Saúde Pública (SESP), para a erradicação da malária (VILARINO, 2008, p. 34). A partir desta atmosfera de desenvolvimento, higienização e crescimento, as camadas da classe média da cidade passam a adotar um discurso de modernidade, presente em relatos orais, ao mesmo tempo em que configuram uma suposta tradição social calcada no prestígio das famílias da classe média denominadas de pioneiras, e responsabilizadas, em relatos de memorialistas, pelo progresso “modernizante” de Governador Valadares (GENOVEZ; VILARINO, 2010).

A presença do rio Doce na história da cidade e do bairro é uma constante. É a partir do rio que surgem não apenas o processo de ocupação territorial, mas, também, de demarcação 
e orientação na formação dos demais bairros (SIMAN, 1988, p.79). As áreas mais valorizadas em termos imobiliários situam-se numa parte mais elevada do terraço e espraiam-se nas imediações do São Tarcísio formando o Centro de Governador Valadares, que é também um bairro. No entanto, a idéia de "centro", do ponto de vista de pulso econômico e comercial, irá abarcar uma área concêntrica envolvendo vários bairros como, por exemplo: Bairro de Lourdes, Bairro Nossa Senhora das Graças e Bairro Esplanada. As áreas mais desvalorizadas e de risco serão aquelas situadas em proximidade de encostas em declive e da margem do rio Doce.

É nesta medida que, enfocando o processo de produção e reprodução simbólica existente no bairro São Tarcísio, propomos utilizar os dados coletados numa pesquisa etnográfica, juntamente com dados bibliográficos existentes sobre a cidade. O objetivo é compreender, através de relatos dos ribeirinhos, o bairro e o rio Doce enquanto território único para eles. A compreensão de determinado processo de produção simbólica num território pressupõe considerar, preliminarmente, certos códigos de conduta, de natureza cultural e social. Por "produção" e "reprodução" simbólica, consideramos determinados aspectos históricos e sociais de geração e transmissão de condutas e convenções (ELIAS, 1990, p. 14). Entretanto, neste processo, a produção e/ou reprodução não se daria de forma ininterrupta, estável e uniforme no território. Assim como a cultura possui um aspecto dinâmico, estas convenções e condutas permitiriam a porosidade, a diversidade e a contradição, uma vez que a sociedade é passiva de influências diversas (WILLIAMS, 1969, p.20). Desta forma, entendemos de antemão que o aspecto da heterogeneidade e elasticidade destes códigos precisaria ser considerado se queremos estudar determinado objetoterritório social, cultural e geográfico, como é o caso do Bairro São Tarcísio, foco central deste ensaio.

Em termos de justificativa, a contribuição pretendida deve ser ressaltada na medida em que ainda não se produziu obra acadêmica que articulasse um diálogo entre História, Geografia, Sociologia e Antropologia capaz de subsidiar os Estudos Territoriais na mesorregião do Vale do Rio Doce e que tivesse como referência teórica o pensamento de Max Weber, Norbert Elias e Paul Claval, os principais autores que norteiam as matrizes teóricas desta pesquisa. É preciso salientar ainda que, apesar dos avanços da Geografia Cultural, as pesquisas voltadas para a microescala territorial ainda caminham a passos lentos. De forma geral, os códigos particulares são negligenciados e privilegiam-se os estudos focados nas grandes cidades o que, em muitos casos, dificulta a verificação da constituição de territórios específicos (SILVA, 2006, p. 22). Entendemos a priori que, para se compreender a lógica destes códigos, tanto na cidade como no bairro, devemos nos pautar pelo processo de constituição histórica da região e pelo desenrolar da vida cotidiana no bairro, considerando-se o universo cultural que lhe dá sentido. 
Do ponto de vista metodológico, estamos cientes de que é ilusória a pretensão de captura da totalidade de um real social, sabemos dos desafios e das limitações de um trabalho como o nosso, uma vez que todo recorte é apenas um fragmento da realidade (SIQUEIRA, 2005, p. 35). Assim, sem nos esquivarmos de utilizar alguns dados quantitativos interessantes para a contextualização do nosso objeto de estudo, recorremos à pesquisa qualitativa como recurso central (GUNTHER, 2006). O nosso objetivo principal é o de verificar a possível existência de um processo de produção e reprodução simbólica através de condutas e concepções de vida dos ribeirinhos, envolvendo o rio Doce e o São Tarcísio. Além dos relatos dos moradores, recorremos pontualmente a outras fontes, tais como fotografias, dados quantitativos (sobre o bairro), e uma série de artigos do jornal valadarense Diário do Rio Doce, apresentando bairros da cidade, publicados na década de 2000, e que se prestem à compreensão do território pesquisado. Quanto ao método de análise (Estudo de Caso) fundamos a nossa interpretação na etnometodologia (GUNTHER, 2006). Em nosso trabalho de campo, os dados foram anotados e organizados juntamente com o material colhido após as entrevistas e serviram como referência em nossas visitas. ${ }^{1}$

\section{Diálogos Epistemológicos Subsidiários Dos Estudos Territoriais}

Ao nos voltarmos para a pesquisa de campo, nossa análise centrará na "interpretação da interpretação" (GEERTZ, 1989, p.23). Justificamos o método de análise escolhido através da compreensão de que a abordagem interpretativa adotada, a etnometodológica, é essencial para compor quadros de referências significativas sobre saberes locais, ao possuir uma perspectiva de análise abrangente para uma leitura interpretativa da realidade. Assim, acreditamos que este método possua características interdisciplinares que possam permitir a busca e a utilização de conceitos teóricos não apenas da Geografia, mas, também, da Sociologia, da Geografia Cultural, da História, da Antropologia, e da Psicologia numa "descrição densa" (MARQUES, 2005, p. 14). Apropriando-se do conceito do círculo hermenêutico, Clifford Geertz (1989, p. 26), prescreve a "descrição densa" e uma "epistemologia prática do bom senso", ou seja, "do senso comum" como recursos para a etnometodologia numa "refiguração do pensamento social", uma vez que as "províncias do

\footnotetext{
${ }^{11} \mathrm{O}$ Material coletado em campo encontra-se preservado na íntegra: dez horas de entrevistas gravadas com trinta pessoas, dentre as quais consideramos vinte e duas para sustentar esse ensaio. Foram arquivadas também as anotações de campo. Dadas as circunstâncias de violência no bairro optamos por não nomear os informantes e trabalhar os dados de forma circunstanciada ilustrando os aspectos teórico-metodológicos proposto neste ensaio. Os critérios para definirem o grupo de entrevistados seguiram o seguinte padrão: residentes em ruas próximas e mais afastadas (por elevação) do rio, com idades acima de 18 anos. A idade dos moradores e o tempo de residência (mais de cinco anos) no bairro constituíram-se elemento importante em nossa pesquisa, que se voltou para um recorte temporal de 10 anos, ou seja, buscamos a compreensão das práticas, representações, territorialidades e códigos culturais, dentre outras possíveis categorias teóricas passíveis de estudos e pressupostamente existentes no bairro, tomando como referência temporal a década de 2000. Primamo-nos, no processo de transcrição de dados, amparados em Geertz $(1989$, p.28) em detalharmos literalmente todos os sinais indicando entonações, sotaques, regionalismos e "erros" de fala.
} 
pensamento" são demarcadas, adquiridas e mantidas dentro de um processo histórico. $\mathrm{O}$ autor argumenta que a cultura não é codificável, mas interpretável. O homem é concebido por ele como um "animal suspenso em teias de significado" que ele (o homem) tece/teceu ao longo de sua existência social e histórica. Desta forma, a cultura seria formada por práticas culturais, convenções simbólicas, códigos explícitos e implícitos, identidades territoriais (GEERTZ, 1989, p. 31-36).

Para a Antropologia Interpretativa, referência que é bastante utilizada em metodologia de trabalhos de Geografia Cultural, é na parte e não no todo que reside o caráter diferenciador da análise. Desta forma, o interesse está focado no próprio termo enquanto individualidade (CLAVAL, 1999a, p. 78). De acordo com Claval (1999a, p. 79), há que se considerar que o sentido é sempre um sentido e, "para compreendê-lo significa compreender para quem o sentido se faz". Desta forma, a interpretação do analista concorre com a interpretação do interpretado, influencia e é influenciada pela compreensão cultural. A "fala dos entrevistados" seria, portanto, analisada dentro de um "imaginário social" e de uma possível "formação discursiva". Desta forma, é através de narrativas e da observação de campo que buscamos compreender o significado que estas pessoas imprimem à realidade objetivando uma possível "construção cultural" que estivesse relacionada ao territóriobairro, ao território-rio e ao território-cidade (GEERTZ, 1989, p.15; MARQUES, 2005, p.5).

Assim, na tentativa de significar o local pela narrativa descritiva usaremos termos que são os mais próximos possíveis daqueles usados pelos atores sociais. Consideramos preliminarmente que no mundo do bairro São Tarcísio exista uma ordem particular de organização sociocultural e territorial. A interpretação e análise levaram em consideração não somente a cena do objeto pesquisado, como também a relação entre esta e o contexto da cidade de Governador Valadares. Neste sentido, compreendemos a sociedade como um conjunto de interdependências entre os indivíduos e relações que se modificam e evoluem sempre perpassadas por tensões geradoras de desequilíbrios e formas frágeis de integração, cujo desenvolvimento social de longo prazo não são planejados e nem previsíveis, imersas num processo de renovação incessante (ELIAS, 1990).

Isto posto, nos cabe discutir teoricamente a categoria território através da Geografia Cultural e de um diálogo interdisciplinar com a Sociologia e a Antropologia. Ao fazermos isso, é intuito nosso relacionar o território à idéia de processo (não apenas geográfico, mas, também, histórico, social e cultural). O esforço aqui proposto é o de construir as bases teóricas para a interpretação cultural do nosso objeto de estudo considerando um complexo processo de produção simbólica e códigos culturais onde o vínculo motivacional da territorialização poderia ser rastreado a partir de uma dimensão processual configuradora não apenas da cultura do bairro, como, também, da cidade de Governador Valadares e da região (CLAVAL, 1999a; WEBER, 1992; ELIAS, 1990). 
Tendo em vista a consideração de que a pesquisa é direcionada a um recorte espacial, optamos por uma discussão que se dá muito mais do ponto de vista teórico do que propriamente interpretativo. Por que utilizamos como área de conhecimento referencial a Geografia Cultural? Porque esta área da Geografia Humanística se dedica à descrição dos fenômenos percebidos pela consciência, podendo estes mesmos, serem diferentes em si (CLAVAL, 1999b, p.58). Como área interdisciplinar, a Geografia Cultural é adotada como ponto de condensação ou convergência destas categorias, uma vez que é pluricêntrica, ao refletir sobre a cultura e as relações do homem e a natureza (FAZENDA, 2006).

$\mathrm{Na}$ Geografia, os estudos que consideram a categoria território apontam várias possibilidades de estudos. A categoria território tem sido utilizada tanto pelas ciências naturais como pelas ciências sociais. Nas ciências naturais, o seu conceito foi formulado pela primeira vez, ainda no século XVII, a partir de estudos da Botânica e da Zoologia. Além disso, o território significava não só as condições de trabalho, mas a própria condição de existência de uma sociedade, definindo-se pela propriedade, isto é, uma área dominada por alguém ou pelo Estado. Diante das constantes mudanças políticas, econômicas, sociais, culturais e ambientais atuais, as questões inerentes ao território emergem com bastante vigor.

Desta forma, considerando o diálogo interdisciplinar entre as várias ciências Haesbaert (2004, p. 40-41) propõe uma divisão das quatro principais vertentes do estudo territorial. São elas: a) política ou jurídica-política, na qual o território é visto como "um espaço delimitado e controlado, através do qual se exerce um determinado poder na maioria das vezes [...] relacionado ao poder político de Estado"; b) cultural ou simbólico-cultural, na qual prioriza a dimensão simbólica e mais subjetiva e o território é visto como o "produto da apropriação/valorização simbólica de um grupo em relação a seu espaço vivido"; c) econômica, que enfatiza a dimensão espacial das relações econômicas, onde o território é visto apenas como fonte de recursos e/ou incorporado no "embate entre classes sociais e na relação capital-trabalho"; d) por fim, a última vertente seria a natural, na qual a noção de território teria como base a relação sociedade-natureza. Neste trabalho, adotamos a vertente cultural ou simbólico-cultural (significado) considerando, também, os aspectos materiais (significante) (GOMES, 2004, p.21).

Ao considerarmos que a essência cultural que orienta as atitudes e ações de um determinado grupo social materializa-se no espaço, mediada por códigos específicos, entendemos que para acessar a simbologia presente neste grupo através de suas percepções sobre o território, seria necessário então conceber não apenas o caráter subjetivo (das pessoas a serem estudadas), mas o próprio processo histórico, geográfico e social do qual o objeto (território) faz parte. Ao propormos inicialmente um estudo considerando o bairro São Tarcísio, como recorte espacial, podemos considerar que a constituição informal das ruas, a existência de vielas, e a presença marcante do rio Doce na vida de seus moradores, 
constituíram traços que podem ser interpretados como portadores de uma importante essência cultural material presente naquele território. Por outro lado, compreendemos que os valores, os comportamentos ribeirinhos e as convenções daquele grupo podem ser estudados como signos imateriais que fazem parte do processo social, histórico e geográfico que aquele bairro apresenta.

Dessa forma, no âmbito da Geografia Cultural, estes códigos constituem-se numa simbologia responsável pela visibilidade da cultura e, também, pela sua transmissão. Assim, encontram-se eles impressos no local de moradia, no estilo das casas, no vestuário típico, na arte, na gastronomia, na música, na religiosidade e nas festividades. Além desses, existem outros códigos que, embora não sejam visíveis, também são responsáveis pela materialização da cultura no espaço, como aportes culturais, com destaque para os valores, comportamentos, ideologias e convenções (CLAVAL, 1999b). Por valores, podemos considerar as crenças e as normas abstratas de comportamento, geralmente, de domínio social e religioso. As ideologias e convenções podem ser entendidas como construções inseridas dentro de um determinado processo que resulta, muitas vezes, num hábito presente nas relações de dominação social (CLAVAL, 1999b, p.26).

No Bairro São Tarcísio, direcionamos nosso trabalho etnográfico considerando, primeiramente, dois grupos: o dos "moradores antigos" e o dos "moradores novos" (ELIAS; SCOTSON, 2000). Contudo, pudemos perceber a existência de outros grupos, tais como aqueles que têm por opção religiosa a religião católica e o grupo dos evangélicos. Observamos, também, a presença de um grupo que mantém o tráfico de drogas, principalmente de cocaína e craque. Percebendo, então, as muitas formas de se apropriar materialmente e imaterialmente do espaço e verificamos inicialmente uma multiterritorialidade naquele bairro. Neste sentido, o termo territorialidade, pode ser aqui compreendido como uma forma ímpar de se apropriar, valorizar simbolicamente, fazer uso da terra e do território e envolve também relações de poder (SAQUET, 2003, p.46). Isto se daria pelos significados e ressignificações que os sujeitos vão construindo em torno de suas experiências de vida, convenções e valores em cada localidade. Para Claval (1999b), esses códigos, cunhados no interior da cultura, referem-se, basicamente, a um sistema de ideias que orienta culturalmente o comportamento dos indivíduos e da sociedade no que diz respeito ao prestígio, responsabilidade, admiração e autoridade.

Do ponto de vista semiótico, a relação cultura-espaço também exerce influência direta no código cultural, pois requer formas específicas de acordo com os elementos naturais que atuam sobre determinados locais. Partilhar os mesmos códigos pressupõe assumir uma identidade comum que, segundo Claval, (1999b) orienta procedimentos de regulação social assegurando a sobrevivência e reprodução do grupo social. Entretanto, é preciso salientar que estes códigos, apesar de configurarem-se como convenções simbólicas partilhadas por 
uma mesma comunidade social como a do bairro São Tarcísio, não são estáticos, mas constantemente reconstruídos no processo social (CLAVAL, 1999b, p. 23).

No caso do São Tarcísio é isso que podemos perceber. Aquele território, até então considerado como um espaço ribeirinho apropriado como 'Porto de Canoas' (século XIX) e, depois, destinado a abrigar precariamente alguns trabalhadores da ferrovia Vitória-Minas que chegaram a Governador Valadares na primeira década do século XX, sofre, na década de 1950, um processo de transformação e mudança com a chegada de novos moradores, também ribeirinhos, oriundos da região e de cidades vizinhas. São outros trabalhadores que chegam a Governador Valadares para trabalhar na extração da madeira e da mica. Muitos destes, vindos de localidades em que viviam próximos a rios e córregos, trazem consigo uma vivência ribeirinha que é (re)produzida no São Tarcísio através de uma (re)territorialização, mostrando todo o caráter dinâmico e de plasticidade das culturas na incorporação de novos elementos (CLAVAL, 1999b, p.27). De maneira geral, não há rompimentos bruscos e sim uma substituição de alguns códigos que permitem ao grupo social manter-se unido culturalmente ao longo do tempo e do espaço. A dinâmica sócio-espacial exerce, então, forte influência na construção e manutenção dos códigos culturais, acarretando transformações, visando sua (re)adaptação às novas realidades que se configuram. Neste contexto, percebese que há uma estreita inter-relação entre cultura-identidade-código, uma vez que esta associação permite ao grupo social identificar-se pelos demais, mediante a formação e materialização das características culturais singulares, emanadas pela cultura.

Com base nestes pressupostos, podemos perceber que os códigos culturais presentes nas relações sociais podem caracterizar uma determinada tradição verificada, do ponto de vista imaterial, através de comportamentos compartilhados por meio de um habitus social através de convenções (ELIAS, 2001, p.28; WEBER, 1996; CLAVAL, 1999b). Isto caracterizaria aquilo que podemos denominar de território simbólico. Do ponto de vista material, os códigos culturais estariam presentes na materialidade verificada, principalmente, na forma e produto da apropriação do espaço na constituição do território visível. Nas duas situações é preciso destacar a ideia de processo e da não permanência; de circularidade e da não linearidade; de movimento e da não estagnação. Desta forma, um território seria o registro de um processo de mudança, de uma transformação, de uma figuração entre o antes e o depois. Interpretar a cultura no território significaria, então, interpretar estes códigos culturais tanto do ponto de vista material (através da paisagem, do estilo das casas, por exemplo), como do ponto de vista imaterial (através de mitos, representações sociais, ritos e imaginários sociais). Neste sentido, os processos de territorialização e de reterritorialização podem ser entendidos como de produção e de reprodução simbólica porque constroem e reconstroem territorialmente, assim como o processo de desterritorialização pode ser considerado como desconstrução, não no sentido de destruição, mas, de reconfigurações (HAESBAERT, 1999, p.14). 
A seguir, apresentaremos uma discussão sobre o que seria um cenário territorializável. Esta discussão é importante porque considera o espaço e as práticas espaciais que constituem ou não determinado território.

\section{O Território e o Cenário Territorializável}

Para estudarmos o sentido do território proposto, interessa-nos compreender até que ponto, o eixo constituído pelo Bairro São Tarcísio, o rio Doce e os ribeirinhos, hipoteticamente, encontra-se, enquanto cenário territorializável, imersos em um complexo processo de produção simbólica. Mas o que seria este cenário territorializável? Podemos, inicialmente, entender um "cenário territorializável" como um espaço geográfico sendo este, vagamente associado a uma porção específica da terra identificada seja pela natureza, seja por um "modo particular como os seres humanos imprimiram ou imprimem culturalmente as suas marcas" (CLAVAL, 1999a, p. 25). Desta forma, a palavra "espaço" tem o seu uso associado indiscriminadamente a diferentes escalas, global, continental, regional, da cidade, do bairro, da rua, da casa e de um cômodo no seu interior (CORRÊA, 2008, p. 15). Segundo Coraggio (1979, p. 8), uma organização espacial pode ser entendida como expressão que equivale a uma configuração espacial, arranjo espacial, socialmente produzido ou, somente, espaço. Além da materialidade que serve de matéria prima ao território sendo, portanto, um cenário territorializável, o espaço carrega um caráter subjetivo e cultural.

Para Yi-Fu Tuan (1983, p.112), este tipo de espaço é também uma "resposta do sentimento e da imaginação às necessidades humanas fundamentais. Desta forma, este cenário, difere do espaço concebido de forma pragmática". Ainda nesta perspectiva, o espaço vivido é uma experiência contínua, egocêntrica, um espaço de movimento "e um espaço-tempo vivido [...] que [...] se refere ao afetivo, ao mágico, ao imaginário” (HOLZER, 1992, p. 440). O espaço vivido é também um campo de representações simbólicas, rico em simbolismos que vão traduzir: "em sinais visíveis não só o projeto vital de toda a sociedade, subsistir, proteger-se, sobreviver, mas também as suas aspirações, crenças, o mais íntimo de sua cultura" (ISNARD, 1982, p. 71). As representações sociais, assim, redundam em práticas. Estas ações, espacialmente localizadas, possuem um caráter social e geográfico e fazem parte de um processo de produção simbólica (CORRÊA, 2008, p.113).

Para Haesbaert (2008, p. 177), as práticas espaciais - resultantes da consciência de diferenciação espacial - são, na verdade, elementos constituintes de processos relacionados ao território e à territorialização, no sentido de apropriação do espaço. Entendendo a territorialização como um processo, esta seria o enraizamento/controle, a edificação territorial tanto material quanto simbólica, mas, também a segregação sócio/espacial, o fechamento, o conservadorismo. A diferença entre um arranjo territorial, como a do espaço 
de um bairro, por exemplo, e a de um aglomerado estaria no fato que o "aglomerado" é "disfuncional, sem identidade ou com identidade fluida". Já o arranjo territorial pressupõe uma rede da qual o indivíduo participa, da mesma forma que a um grupo ou classe, sendo "funcional e simbólica", com identidade individual e/ou global (HAESBAERT, 2008, p.178180). Nesta direção, o arranjo de um território pressupõe, portanto, o de uma "comunidade" onde ocorrem interdependências de funções e regulação do comportamento.

Em síntese, consideramos o espaço geográfico como matéria-prima formadora do território e este pressupõe uma apropriação, um processo de territorialização tanto material quanto imaterial. No que se refere ao caráter imaterial, consideramos os comportamentos sociais, os sentimentos, os códigos de convivência, as experiências compartilhadas, enfim, os simbolismos individuais e coletivos que, pertencendo à esfera das representações e do imaginário sociais, se concretizariam em práticas espaciais. Estas práticas fariam, então, parte dos processos de apropriação territorial e se concretizariam na materialidade do espaço apropriado, ou seja, do território. Então, além da territorialização, a desterritorialização (no sentido de evasão; abandono) e a reterritorialização (no sentido de recomposição, reconstrução territorial) são também processos permeados de significados e de um sentido cultural (HAESBAERT, 2008). Com base nestes pressupostos, o território seria o produto de uma cena territorializável através da apropriação material do espaço, mas, esta apropriação seria, também, simbólica, relacionada ao imaginário, à experiência, ao mítico, ao vivido e aos códigos culturais.

No próximo tópico, veremos como estes processos de apropriação territorial podem ser compreendidos de produção e reprodução simbólica ao considerarmos que os códigos culturais podem ser construídos, reconstruídos, mantidos, (re)significados, expurgados, ou esquecidos, influindo sobremaneira na constituição ou não do território.

\section{A Cultura em Interlocução Com a Territorialidade: o Rio, o Bairro e os Ribeirinhos}

Buscando um diálogo interdisciplinar, partimos, nesta altura, em busca da compreensão do complexo processo de produção simbólica envolvendo a cidade de Governador Valadares, através de algumas referências teóricas. Em outras palavras, interpretar uma cultura de uma dada comunidade, como a de um bairro, pressupõe, então, mergulhar nos códigos que a constituem. Salienta-se, neste caso, que a cultura se expressaria em territorialidades considerando-se, portanto, as relações sociais que produzem o espaço. São estas relações que seriam marcadas pelos códigos que emprestam um sentido particular no processo de produção simbólica do território (CLAVAL, 1999c, p. 4; MELLO, 2009, p.16). 
Além do conceito de cultura, que abre um leque de diálogo entre Geografia Cultural e outras disciplinas, a categoria territorialidade pode ser considerada como outro vetor de comunicação interdisciplinar (CLAVAL, 1999b, p. 34). Isso é possível quando consideramos que a territorialidade, compreendida como apropriação do espaço, pressupõe diversas possibilidades de ocupação, relação, e "legitimação" deste mesmo espaço (WEBER, 1996, p. 27; HAESBAERT, 2004, p. 40). Enquanto "locus" de códigos culturais e, dentre eles, os costumes e as próprias relações de poder, pode-se dizer que o território, resultado do espaço apropriado, está em constante movimento. Um movimento em que o espaço pode ser considerado como cenário e matéria-prima deste processo (CORRÊA, 1994, p.29). Neste sentido, consideramos que é no território, sendo ele uma rua, um bairro ou uma cidade, que acontece a construção, regulação e auto-regulação de identidades (ELIAS, 1990, p.14). Estas, por sua vez, são agenciadas pelos códigos (BEZZI, 2004, p. 10). Para compreender estes códigos, necessário se faz considerar que a cultura pressupõe a articulação de identidade e representações presentes, muitas vezes, no âmbito de um discurso. Desta forma, podemos inferir que a cultura permeia uma comunidade orientando suas ações e relações com o espaço (WEBER, 1991, p. 57). São no espaço que se materializam as características distintivas e culturais as quais pressupõem símbolos comuns, funcionando como mecanismos de reconhecimento entre os membros de um mesmo grupo social, ao mesmo tempo em que os diferem dos demais (ELIAS, 1990, p. 46).

Para Claval (1999a, p. 56), estes "símbolos", denominam-se códigos culturais e, englobam desde a linguagem até as convenções mais particulares de cada cultura. De certo modo, permitem a sobrevivência de um grupo cultural e têm como resultado do processo de produção simbólica, a organização de um espaço o qual se torna característico via materialização dos códigos que compõem esta cultura. Pode-se dizer, com base neste referencial, que a territorialidade em seu aspecto cultural consistiria, basicamente, num conjunto de crenças e valores que orientam ações num determinado espaço, de um determinado grupo social, a partir dos sistemas simbólicos que o torna distinto dos demais, conferindo-lhe características singulares. Estas, por sua vez, definiriam o grupo social através do contraste, originando a identidade (ELIAS, 1990, p. 37).

Ao estudarmos o bairro São Tarcísio, percebemos que a territorialidade em seu aspecto cultural constitui-se, basicamente, num conjunto de crenças e valores que orientam ações (materializadas ou não) num determinado espaço, a partir dos sistemas simbólicos que tornam aquela comunidade distinta das demais, conferindo-lhe características singulares. A maneira como o espaço foi apropriado, dotou o bairro de uma carga cultural a ser captada numa interpretação dos sentidos deste território. O rio Doce ocupa, nesta medida, um importante papel como aglutinador de referências simbólicas. Dessa maneira, o bairro pode ser visto como um território composto por micro-territorialidades. Elas podem ser compreendidas como identidades caracterizadoras de pequenos grupos, como, por exemplo, o dos "moradores velhos" e o dos "moradores novos", os "traficantes", os "não traficantes". A 
população que ocupou o São Tarcísio foi constituída historicamente, em sua maioria, de "forasteiros", ou seja, aqueles que chegaram a Governador Valadares sem bens, sem nome, muitas vezes sem família e, por causa disso, considerados aventureiros e desenraizados. Para eles, os espaços aterrados de baixada e sem nenhuma infraestrutura, se constituíram numa opção de moradia. Os espaços mais favorecidos e valorizados, que já possuíam alguma urbanização, protagonizaram um tipo de nucleação urbana tornando-se centrais no processo que gerou a periferia.

Portanto, o território batizado de bairro São Tarcísio se iniciou por meio de um processo de reprodução dos costumes rurais com regras de convívio, expectativas e afetos, principalmente do ponto de vista espacial, por causa da proximidade com o rio Doce. Este processo pode ser caracterizado pela adaptabilidade, pelo ajustamento e pela maleabilidade. Ainda no século XIX, o espaço do atual São Tarcísio recebeu moradores canoeiros por causa de um porto de canoas que, naquela altura, referenciava regionalmente a localidade que originou Governador Valadares (ESPINDOLA, 2005). Mais tarde, por volta da primeira década do século XX, outros moradores territorializaram o espaço: eram os trabalhadores da estrada de ferro Vitória-Minas. Até que na década de 1950, o espaço recebeu, enfim, os moradores que constituíram as bases de formação daquela comunidade.

O processo de territorialização esteve, portanto, alinhavado por um "tipo de motivo" (um padrão de ação) (WEBER, 1996, p. 67). Neste encadeamento (sucessão/sequência) é preciso que consideremos uma hipotética motivação (motivo/ação) nem sempre consciente, desencadeadora e orientadora do processo. Entendemos que a motivação que teria originado o processo de territorialização do Vale do Rio Doce e, consequentemente, da cidade de Governador Valadares e do bairro São Tarcísio, baseou-se num tipo de tradicionalismo em termos de apropriação espacial. Assim, a produção simbólica deste território envolveria aspectos ligados ao imaginário e à forma de organização espacial estabelecida ainda no período colonial. Primeiramente, a demarcação territorial da região, não apenas do Vale do Rio Doce, mas, também, do Mucuri e do Jequitinhonha, se deu a partir dos rios. Em segundo lugar, a violência verificada no processo de colonização do Sertão do rio Doce tanto no primeiro estágio, com as Divisões Militares e a "guerra dos botocudos", quanto na etapa seguinte, com a ação dos fazendeiros e matadores de aldeia, nos revela que a propriedade rural e a questão da apropriação de terras, impõem-se como símbolo de poder e status. É a terra que, em termos econômicos, propicia a exploração de recursos naturais e estabelece, inicialmente, uma economia agro-comercial. Será a terra que estabelecerá, também, balizas de demarcação física e territorial na cidade de Governador Valadares, valorizando determinadas áreas e desvalorizando outras. Nesta "terra de oportunidades" verifica-se, no século XIX, uma aliança entre os fazendeiros e as Divisões Militares, garantindo, mesmo que não oficialmente, uma relação de favorecimento em troca de lealdade. Em terceiro lugar, verifica-se a estratégia de manutenção de um poder centrípeto (em sentido partindo do centro) onde, atualmente é a região do Vale do Rio Doce, através de fiscalizações e controle 
do território por parte da Coroa. Entretanto, exceto no caso da demarcação de pontos estratégicos pelas Divisões Militares do Rio Doce, verifica-se, na prática, a existência de um tipo de poder centrífugo (no sentido de fuga do centro), especialmente após a "guerra dos botocudos", onde houve uma orientação recíproca de agentes locais tais como fazendeiros, aventureiros, praças, garimpeiros, matadores de aldeia e índios remanescentes, num tipo de autonomia onde suas ações conjugaram um mesmo processo de territorialização e apropriação dos espaços. Isso teria criado uma primeira polarização em termos de grupamentos: os fazendeiros, poderosos que contavam com o apoio dos praças das Divisões Militares que, em raras ocasiões, garantiam proteção aos remanescentes indígenas já praticamente dizimados pela guerra, e um outro grupamento pobre, formado por mestiços (pardos) e negros pobres, garimpeiros, aventureiros, prostitutas, pequenos comerciantes de sal e coletores de drogas do sertão, dentre outros. Será este grupamento menos favorecido, contando ainda com os índios mestiços e migrantes, que formará, num primeiro momento, o território inicial dos bairros com localização menos privilegiada de Governador Valadares. Num segundo momento, os ciclos econômicos da cidade atrairão mais pessoas de regiões vizinhas e mais distantes, principalmente trabalhadores entre as décadas de 1940 e 1950, na etapa da exploração da madeira e da mica. A relação entre os dois grupamentos (favorecidos) e (não-favorecidos) se selará por meio de uma interdependência social formando uma teia que definirá uma polarização em Governador Valadares.

Em outras palavras, as representações coloniais a respeito do rio Doce ("caminho de riquezas", "área proibida", "possivelmente navegável", "fronteira de demarcação") e do sertão ("vasto", "ermo", “desconhecido", "habitado por botocudos antropófagos", "desconhecido", "perigoso", "enigmático") carregaram consigo uma ideologia porque participaram de um processo de dominação (ESPÍNDOLA, 2005, p. 414). Esta ideologia se presta, assim, à fomentação de uma "teia de significados" que desvela o contexto de formação da cidade. Este contexto apresenta sentidos espaciais e não espaciais. Em termos espaciais, as terras demarcadas do sertão serviram de suporte ao povoamento da futura Figueira (posteriormente, Governador Valadares). No início do século XX estas terras eram conhecidas como "terras do patrimônio" e formavam um semicírculo de 60 alqueires em volta da margem esquerda do rio. Com o avanço da estrada de ferro Vitória-Minas, a região se viu transformada: as florestas destruídas, os índios remanescentes afugentados e os pequenos lavradores, destituídos dos seus bens. A ocupação das terras devolutas trouxe para o cenário territorializável a presença de pessoas e, com ela, as relações hierárquicas de poder entre coronéis, posseiros, retirantes, trabalhadores rurais, prostitutas e tropeiros.

Voltando-nos neste momento mais especificamente para o bairro São Tarcísio, facilmente identificado pela particularidade geográfica que o reveste: pequeno e situado em uma das partes mais baixas da cidade de Governador Valadares que margeia o rio Doce, apresenta pouco mais de uma centena de imóveis e é um dos primeiros locais atingidos pelas enchentes de Janeiro. É estigmatizado através de matérias em jornais locais que 
difundem a imagem da violência e do tráfico de drogas, fornecendo representações de uma realidade frequentemente associada ao ambiente semiperiférico brasileiro, em que as matrizes de desigualdades sociais sobrepõem-se aos acúmulos de déficits históricos materializados nas condições de vida de uma parte expressiva da população. Trata-se de um bairro pobre onde a posse de uma casa/terreno se constitui no principal bem. Os moradores são, em sua maioria, autônomos, aposentados ou desempregados. O desemprego, principalmente no que diz respeito aos jovens, teria agravado o quadro social, favorecendo a presença do narcotráfico e da violência.

Um simbolismo percebido no bairro diz respeito às enchentes. Elas provocam uma reconstrução anual do território como resposta a uma desterritorialização temporária, com a retirada dos moradores de seus lares. Percebemos que a enchente é um fator aglutinador da comunidade através das relações de solidariedade que são estabelecidas entre os ribeirinhos. Apesar de se constituir um problema, percebemos que alguns, mesmo com condições de se mudarem do bairro, preferem continuar morando nas proximidades do rio. Desta forma, o processo de organização social e suas práticas seriam elementos caracterizadores desta territorialização (CLAVAL, 1999a, p. 26).

Figura 2- Enchente no Bairro São Tarcísio

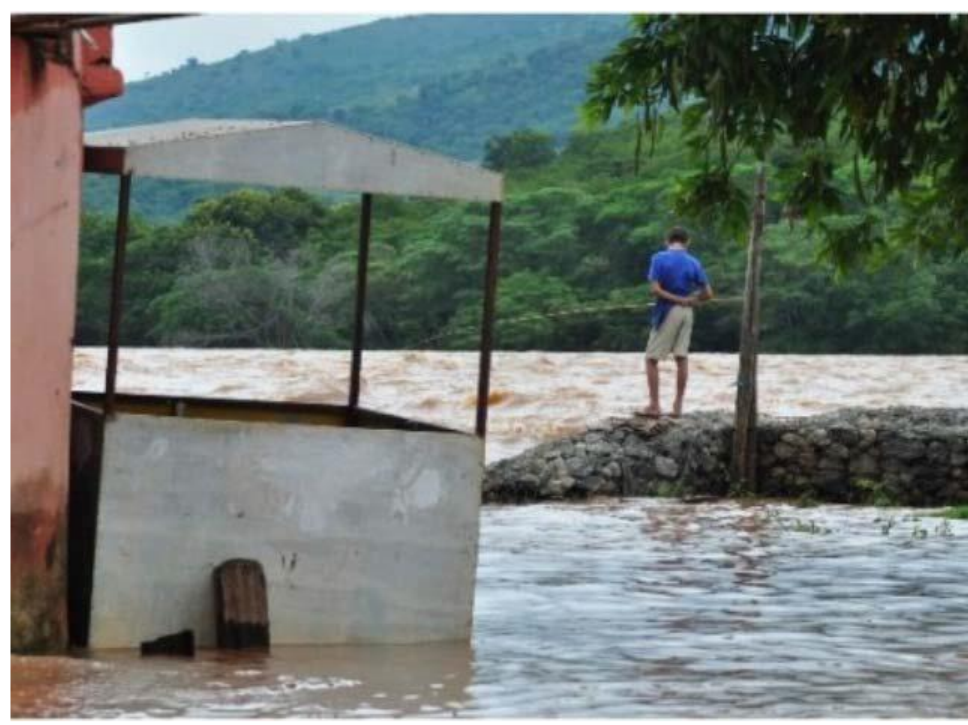

Fonte: Arquivo do jornal Hoje em Dia (2009)

Durante o trabalho etnográfico, as narrativas obtidas a partir das entrevistas nos revelaram uma forma de atribuição de significado ao São Tarcísio através de valores, códigos, normas, atitudes e constrangimentos. As visões compartilhadas sobre vários assuntos que fazem parte do dia-a-dia dos moradores indicaram um mecanismo essencial de 
produção de significado cultural uma vez que elas podem ser consideradas como resultado de uma interpretação que os mesmos fazem da realidade. Isso nos remete à possibilidade de considerarmos a narrativa como uma forma de representação e adjetivação do território e do próprio comportamento social e cultural ao vê-la como um relato que descreve, cria e interpreta, momentaneamente, um determinado processo configuracional. As práticas sociais e seus significados partilhados estariam, assim, relacionados ao processo de organização social e espacial no qual a produção e reprodução simbólica verificada nos códigos mais presentes no São Tarcísio, configurariam uma territorialidade. O motivo que transparece por detrás destes códigos culturais nos daria possivelmente indícios para compreender o desenrolar de um processo que se projeta para o futuro e em que os indivíduos e a coletividade conjugam formas de um imaginário e de representações sobre si mesmo e o território (CLAVAL, 1999a, p. 25). De acordo com esta ótica, objetos sociais e culturais como a realidade dos ribeirinhos que residem no São Tarcísio podem ser construídos e reconstruídos pelos atores interminavelmente. Ou seja, o significado social dos objetos se deve ao fato de lhes darmos sentido no decurso de nossas interações (COULON, 1995, p. 21).

Baseados nestes pressupostos notamos que a "cultura da droga" no bairro apresenta alguns questionamentos quanto à natureza dos espaços públicos e privados: as ruas, que são espaço de convivência entre os vizinhos durante as tardes, em determinadas horas da noite, se transformam em pontos de comércio e encontro dos traficantes. Assim, a rua que é da "vizinhança" passa a ser também o espaço de convivência das "gangues" e das relações que elas mantêm com usuários. Isso nos remete à ideia de uma territorialização do mesmo espaço em horários diferentes, por grupos com uma identidade também diferente, ligada a códigos específicos de conduta e ação próprios dentro da comunidade.

Embora haja uma associação entre violência e o tráfico de drogas, percebe-se que eles não são, necessariamente, equivalentes. O que observamos é a possibilidade de a violência se tornar um código de conduta como meio de resolução dos negócios e conflitos dentro da "cultura da droga". Os crimes violentos estariam associados a contextos em que há "desorganização social", isto é, uma quebra das regras de conduta dentro de determinado contexto territorial. O narcotráfico estaria associado à forma como o espaço foi organizado. Ou seja, aqueles que estão mais próximos da rotina do tráfico gozam de determinados benefícios de acordo com a função que cumpre. Estes benefícios incluem "proteção", "salário", e "salvo-conduto" pelas imediações do bairro. Há, no narcotráfico, segundo os moradores, uma hierarquia de acordo com a função de cada membro. Existem os "traficantes", os "aviões" (crianças e jovens) e os "soldados" (que defendem o território de invasores e da polícia).

Quando refletimos sobre situações sociais como a do São Tarcísio, verificamos que não só os grupamentos sociais são estratificados, mas, também, as relações intersubjetivas. Há 
talvez aí, espaço para os micropoderes que fazem com que todos os sujeitos possam, potencialmente, desempenhar o papel de dominantes e dominados, agressores e vítimas, mandantes e subordinados. Abre-se, portanto, uma possibilidade de proliferação de grupos territoriais mais concisos e, consequentemente, de identidades, uma vez que haveria, neste caso, uma fragmentação dos códigos culturais.

Neste sentido, a territorialização dos espaços de exclusão de Governador Valadares pelos narcotraficantes se faz à custa da possibilidade de desenvolvimento de organizações e forças sociais independentes. A essa territorialização corresponderia, por outro lado, numa desterritorialização pela maior parte da população local. Acreditamos que a "urbanização sem urbanidades" gerou uma organização do espaço em que as margens do rio Doce, não apenas no São Tarcísio, mas, também, em outros espaços da cidade (como é o caso, por exemplo, do bairro São Paulo, Santa Terezinha, Conjunto Sir e a antiga "baixa do quiabo", situada na região do bairro Santa Rita) transformaram-se em locais propícios ao narcotráfico fazendo com que as comunidades destes bairros se tornassem reféns da criminalidade. A fragmentação político-espacial do tecido urbano nos locais dominados por traficantes promove, então, uma nova configuração da cidade. Neste rearranjo, novos sentidos são disseminados do ponto de vista cultural na comunidade. Além dos constrangimentos de uns e, em alguns casos, até mesmo associação, conivência e participação de outros, os contextos territoriais se repartiram em pequenos grupos territoriais conforme as práticas sociais e os códigos de conduta. No caso do rio Doce, ele se constitui, pelo menos no caso do São Tarcísio, num "território de fuga". É por ele que as pessoas fogem da polícia. Assim, o rio ganha, também, a representação de "território esconderijo ou refúgio", muito parecida com a representação disseminada durante o período de colonização no século XIX, que transformava os índios botocudos nos "senhores da margem do rio Doce" por nele saberem se embrenhar e se ocultar das tropas expedicionárias.

Apesar dos "perigos" com o "território da criminalidade", existe um convívio tacitamente respeitoso entre todos, exceto em alguns casos de disputas internas entre traficantes. Em geral, os depoimentos apresentam uma "normalidade" que pode ser entendida como realmente vivida, resultado do costume que se firmou entre as relações interpessoais e intergrupais ao longo do tempo, considerando-se também aí, a proximidade, em alguns casos, facilitada pelas relações de parentesco; ou, então, esta "normalidade" poderia ser entendida como uma expressão que tenta apagar um pouco do estigma de "bairro perigoso" que atualmente marca e demarca territorialmente o São Tarcísio. Assim, segundo os moradores "tudo é normal". Os objetos do mundo social são assim construídos e reconstruídos dentro de uma estrutura de "familiaridade" interpretada através do estoque de conhecimentos que a comunidade tem à mão (HERITAGE, 1999, p. 41). O convívio cordial entre os moradores e o lazer praticado no rio Doce, principalmente pelos jovens e crianças, são elementos que reforçam as relações sociais. Quando falamos em lazer no rio, estamos 
nos referindo especificamente a banhos no final da tarde, pescarias e até mesmo a prática da canoagem.

Outro ponto a destacar com relação aos costumes dos moradores são os trajetos e itinerários que os mesmos percorrem. Alguns deles gostam de passear pelo bairro; outros de visitar o rio Doce, de pescar e de nadar no rio, principalmente ao final da tarde. Tais exemplos nos permitem apreender a territorialidade através das relações sociais e culturais que o grupo mantém com estes lugares, principalmente com o rio. No senso comum, poderíamos imaginar uma "colcha de retalhos", formada de partes altamente desiguais e, por vezes, desconexas, mas que, formariam um todo. Neste caso, o senso comum não seria formado por uma lógica racional, ao contrário, as ações do senso comum seriam muitas vezes irracionais e ilógicas mas isso dependeria, também, do ângulo que nos posicionamos como observadores (WEBER, 1996, p. 32). Enchente e violência não seria um problema para a maior parte dos moradores. A maioria do grupo entrevistado relatou que tem opções de se mudar para outro bairro, mas que, o São Tarcísio é o lugar de sua escolha e, portanto, não há problema algum em morar lá.

Quando o assunto é lazer no rio Doce, é sempre bom seguir, de acordo com os moradores, a sabedoria popular: a "água não tem cabelo", ou seja, pode se tornar perigoso, principalmente com a existência das corredeiras, que não oferecem nenhuma forma de salvamento possível como recurso último em caso de afogamento. Na sabedoria popular, água é apenas água, não tem pontas para se segurar. Da mesma forma que o espaço vivido é uma experiência contínua, egocêntrica e, ao mesmo tempo social: um espaço de movimento e, também, afetivo, marcado por ensinamentos e sabedorias. Concebendo este espaço como um território composto por simbolismos que redundam nas práticas de subsistência, persistência, sobrevivência e aspirações, a cultura seria a junção de tudo isso, considerando estas práticas como que "inscritas em códigos culturais e convenções" (ISNARD, 1982, p. 76). Quando imaginamos todas estas pessoas reunidas num só espaço e comungando de uma forma de convívio seja no lazer ou no trabalho, vemos que o modo como elas agem cotidianamente, pode ser também relacionado a uma acomodação que se efetivou socialmente dentro de um processo. Suas ações possuem um caráter social e geográfico e fazem parte de um processo de produção simbólica do território uma vez que dão a este mesmo território uma marca cultural, social e geográfica (CLAVAL, 1999a, p. 28). Nesta medida, consideramos que as narrativas encerraram uma "prática/realização" (a partir das representações sociais); uma "indicialidade" (a partir dos códigos culturais), uma "reflexividade" (a partir do imaginário social); uma "relatabilidade (ou accountability, a partir dos relatos); e, finalmente, uma "noção de membro" (a partir do pertencimento) (COULON, 1995, p. 14).

Isto posto, a "prática", ou seja, a realização de ações arregimentadas pela maneira como os moradores percebem e enxergam o seu mundo, está relacionada, também, à forma ímpar 
de se apropriar, valorizar simbolicamente e materialmente, fazer uso da terra e do território e, além disso, se relacionar socialmente. Isto se daria por meio dos "significados e ressignificações" que os sujeitos vão construindo em torno de suas experiências de vida, convenções e valores (KOGA, 2003, p. 38). Esta territorialidade, que não é apenas física, mas social e cultural, se torna tão mais forte quanto maior o tempo de moradia no bairro. Vê-se também, neste caso, um exemplo de relatabilidade (accountability) no sentido de que a realidade social é construída na prática do dia-a-dia pelos atores sociais em interação. Desvendar o senso comum seria o mesmo que desvendar as representações sociais e as identidades que orientam, na prática, as ações sociais. Nesta medida, a cultura se expressaria em territorialidades considerando-se, portanto, as relações sociais que produzem o espaço ao longo do tempo. São estas relações que seriam marcadas pelos códigos que constituem um sentido particular no processo de produção simbólica do território (CLAVAL, 1999a, p. 25). Assim, em seus mais de 50 anos de existência como bairro, o São Tarcísio foi/é cenário, matéria-prima de um processo onde acontece a construção, regulação e auto-regulação de identidades (CORRÊA, 1994, p. 34).

O simbolismo que demarca o convívio estaria embasado, também, no tempo de convivência. O rio Doce parece desempenhar um papel aglutinador de todos os códigos culturais. Isso pode ser observado quando os moradores exaltam as "belezas" do bairro, mas, também, no caso das enchentes quando o mesmo rio torna-se um problema. O rio está presente também quando o assunto é o tráfico de drogas, funcionando como uma "rota de fuga ou esconderijo". Quando exploramos a temática da paisagem, tanto o rio como o bairro São Tarcísio aparecem nos relatos de uma forma muito dinâmica. Nesta medida, a noção de paisagem dos moradores é processual porque, por um lado, expressam um sentimento nostálgico (eles falam de outros tempos em que a paisagem era de um jeito e que agora, é de outro), por outro lado, relatam que apesar de encantadora, o "descaso da Prefeitura" e a "poluição" tiram da paisagem tudo o que ela teria de positivo. Assim ela sofre transformações na percepção de quem a vivencia e a vivenciou em outros tempos gerando comparações entre o presente e o passado. Uma comparação sempre presente nos relatos é a de que o rio antes "era limpinho" e agora "está todo poluído". Cabem, portanto, duas considerações: a primeira é a de que as narrativas revelam um profundo encantamento com a paisagem natural em referências ao rio e à visão frontal do Pico da Ibituruna, mas, por outro lado, do ponto de vista do olfato e do uso, o rio Doce "já se tornou", na opinião de alguns um "esgotão"; a segunda consideração é a de que ao reclamarem do rio, moradores revelam que contraditoriamente jogam comida e até mesmo animais mortos no rio, compreendendo que "o rio leva tudo". Assim eles não seriam responsáveis pela poluição. Vêse aí uma visão recortada e congelada do bairro enquanto território que, apesar de processual, parece possuir, pelo menos para os moradores, uma dimensão fixa e esquadrinhada apenas no recorte da localidade do São Tarcísio sem, contudo, abarcar o todo em sua abrangência. 
Quanto a paisagem, o rio aparece como a principal marca do bairro. Já o Pico da Ibituruna, mais distante, aparece como um cenário avistado, que não se tem um contato concreto e imediato, mas que compõe, juntamente com o rio, um cartão postal para quem mora no bairro. As respostas, em sua maioria, sempre trazem a paisagem como o "outro", ou seja, o que se pode apreciar a partir do bairro e não necessariamente o próprio bairro, a não ser quando é destacada a presença das margens do rio Doce. Ao contemplarem a paisagem de suas casas ou mesmo da rua, os moradores do bairro se ligam a ela afetivamente como se a vista postal fosse uma das vantagens de se morar naquele bairro. Esse sentimento reforça os laços de enraizamento e pertencimento de alguns ao bairro. O sentimento de encantamento convive com o de frustração porque "não tem mais peixe no rio". Percebe-se, que a poluição não aparece como complicador da "beleza" do rio, porque o rio é "tudo abaixo de Deus". Nestes relatos é possível indicar que os códigos culturais oferecem fragmentos do mundo social através das redes de significações (COULON, 1995, p.67). Estes significados partilhados estão presentes no comportamento e, também, na linguagem do dia-a-dia unificando, de certo modo, uma determinada expectativa ou sentimento compartilhado tanto de "encantamento" como de "frustração". A linguagem cotidiana, ordinária, presente nestes depoimentos, são repletas de expressões indiciais: nas expressões "o rio Doce é tudo abaixo de Deus", "a natureza como um mistério de Deus" ou mesmo "a natureza é Deus", na dimensão que alguns dos moradores dão à "paisagem" (neste caso a paisagem "outra”, extrabairro) não é nem um pouco insignificante. Elas evocam um encantamento próximo do sentimento de adoração. Na visão do morador, a natureza ganha um caráter místico e incomensurável que o leva a sentir-se gratificado(a) com os benefícios recebidos nesta relação.

Figura 3- Vista do Pico da Ibituruna (ao fundo) e da Ilha dos Araújos a partir do Bairro São Tarcísio

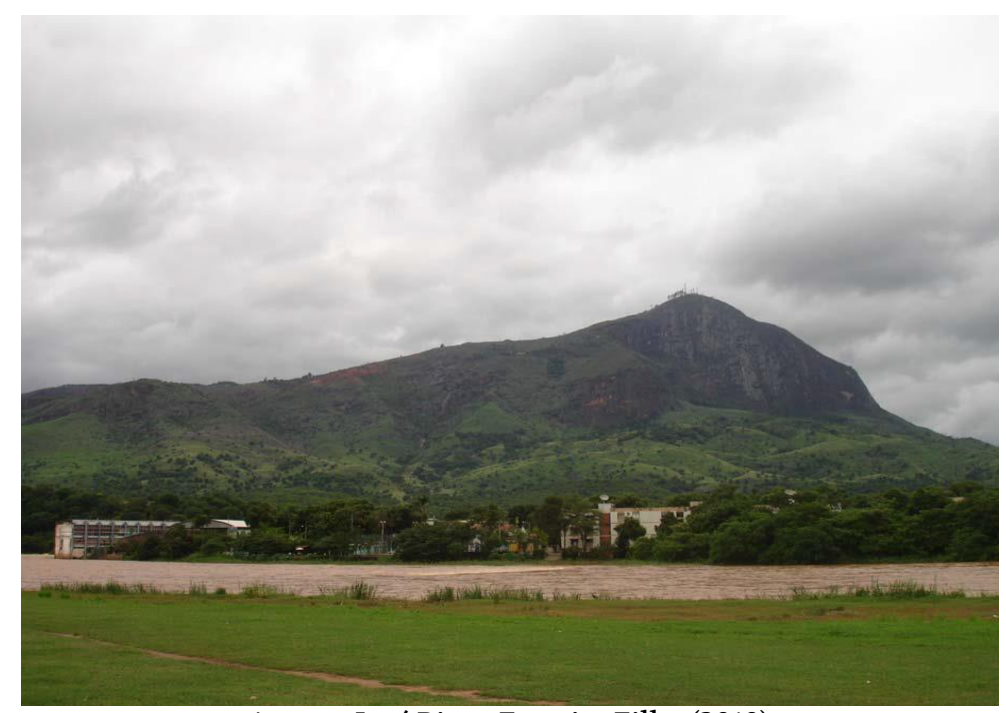

Acervo: José Bispo Ferreira Filho (2010) 
É preciso dizer que ao interpretarmos estas expressões não almejamos de forma alguma cometer generalizações que expliquem a complexidade que existe por trás da subjetividade, oferecendo como resultado da nossa interpretação, uma simples rotulação. O que percebemos é que a apropriação física e cultural do espaço apresenta elementos que a conecta processualmente ao passado de Governador Valadares e do Sertão do Rio Doce, como se as três escalas espaciais e temporais fizessem parte de um mesmo encadeamento. Neste caso, o rio Doce, no caso do sertão, da cidade e da paisagem, teria como denominador comum um sentido de riqueza que não deve ser esquecido. É a riqueza "fabulosa" do ouro, da prata e das pedras preciosas; é a riqueza do território do qual os botocudos são os guardiões; é a riqueza da localização estratégica e do abastecimento de água que viabiliza a apropriação gerando áreas mais valorizadas e menos valorizadas. É desta forma, também, a "riqueza", quando o assunto é a "paisagem". Ela ocuparia um lugar no imaginário dos moradores e não teria uma dimensão apenas de deleite e fruição, mas, também, de "uso". As pessoas utilizam o rio para o lazer, para o trabalho (na pesca, na lavagem de roupas, na extração de areia), ou, até mesmo, para fugir da polícia. Assim, a paisagem (agora, compreendida no sentido do próprio rio) seria uma "beleza" que é cultuada como tal, mas, sem deixar também de considerar o seu lado utilitário.

Por outro lado, as tradições populares existentes no São Tarcísio como, por exemplo, as referências do caboquinho d'água, a Mãe do Ouro, e os "pés antigos", parecem ter sido aprendidas num contexto mais amplo, conforme o relato e ensinamentos dos moradores mais antigos. $\mathrm{O}$ costume dos mais velhos de propagar e, até mesmo acreditar nestas crendices, tem permanecido vivo no bairro em forma de memória. $\mathrm{O}$ "folclore" manifestado no São Tarcísio, da mesma forma que as pessoas têm percepções acerca da paisagem, do convívio, e do trabalho nos espaços ribeirinhos (não nos esquecendo das enchentes), pode, talvez, ser compreendido como resultado de um longo processo de formação e reprodução social/cultural/simbólica dos migrantes que chegaram a Governador Valadares, oriundos da zona rural, na metade do século passado.

\section{Considerações Finais}

O processo de colonização do sertão do rio Doce pode ser considerado um processo de gestão e produção do território, porque produz uma organização espacial e, consequentemente, social. Governador Valadares herdou um padrão cultural de apropriação do espaço que considera nas práticas de dominação espacial, a terra como símbolo de status e de poder social e econômico. É a terra que garante a exploração dos recursos naturais e, ao mesmo tempo, acentua uma seletividade no espaço disponível para moradia dos mais 
favorecidos e dos menos favorecidos. Nesta lógica de distinção social, econômica e cultural entre centro e periferia, o bairro São Tarcísio foi criado, oficialmente, na década de 1950.

O sentido presente no processo de produção e reprodução simbólica no bairro São Tarcísio está relacionado à proximidade com do rio. Os ribeirinhos reproduzem indiciariamente, em situações como lazer, trabalho, convivência, o folclore e os costumes que trouxeram de regiões rurais circunvizinhas a Governador Valadares. Os moradores contribuem, através de suas narrativas, para significar o bairro desvelando uma ordem particular de organização sociocultural e fazendo com que o bairro São Tarcísio, enquanto território simbólico possa ser percebido por meio de aspectos distintos tanto no plano individual como no coletivo.

Ao concluirmos este ensaio, nos chama a atenção os sentidos do território, no que diz respeito à produção e reprodução simbólica interpretada no bairro São Tarcísio. Elas estão relacionadas aos arranjos e rearranjos territoriais que a cidade de Governador Valadares sofreu ao longo de seu processo territorial e histórico, gerando uma lógica excludente em termos de organização social. Dessa forma, a produção dos territórios gerou códigos culturais e práticas espaciais na cidade e, numa escala menor, nos bairros que a constituem. Interpretar a cultura num bairro como é o caso do São Tarcísio, implica apreender a territorialidade expressa nestes códigos e nestas práticas, reveladas por símbolos comuns que podem ser interpretados como mecanismos de reconhecimento grupal. Como o território São Tarcísio não é homogêneo em termos culturais, é preciso considerar que a identidade e a territorialidade presente em pequenos grupos, mais concisos, participariam do "universo cultural" do bairro, mas, de uma forma mais restrita, mantendo particularidades em suas regras e códigos de convivência que configuram um cenário territorializável.

\section{Fontes Orais}

Informações Orais obtidas em campo, realizado no Bairro São Tarcísio, por José Bispo Ferreira Filho entre 2010 e 2011 - relação de nomes fictícios:

- Moradores da Rua Cláudio Manoel:

Fernanda, 73 anos; Adriana, 77 anos; Clara, 65 anos; Sandra, 59 anos; Edílson, 77 anos; Maria, 36 anos; Marly, 66 anos; Vanda, 56 anos; Mariza, 63 anos; Mônica, 66 anos; Adriana, 77 anos.

- Moradores da Rua Adriano Fróes:

José, 46 anos; Nara, 71anos; Rafaela, 26 anos.

- Moradores da Rua Geraldo Vieira dos Santos: 
Leandro, 34 anos; Antonio, 85 anos; Mário, 24 anos.

- Moradora da Travessa Treze de Maio:

Rosa, 90 anos.

- Moradores da Rua Geraldo Vieira dos Santos:

Laura, 42 anos; João, 64 anos; Mário, 24 anos.

- Moradora da Rua Prudente de Moraes:

Verônica, 63 anos.

\section{Bibliografia}

BARROS, Sandra Augusta Leão. O que são os bairros: limites político-administrativos ou lugares urbanos da cidade? O caso de Apipucos e Poço da Panela no Recife. 2002. Dissertação (Mestrado) - Faculdade de Arquitetura e Urbanismo. Faculdade de São Paulo. São Paulo, 2004.

BEZZI, Mari Lourdes. Região: Uma (Re)visão Historiográfica - da gênese aos novos paradigmas. Santa Maria: UFSM, 2004.

CLAVAL, Paul. A Geografia Cultural. Florianópolis: UFSC, 1999a.

A Geografia Cultural: o estado de Arte. In: ROSENDHAL, Zeny; CORRÊA, Roberto Lobato (Org.). Manifestações da cultura no espaço. Rio de Janeiro: EdUERJ, 1999b. p.14- 51.

_ _ _ _ . . O território na transição da pós-modernidade. GEOgraphia, Niterói, n. 2, p. 9-25, 1999c.

CORAGGIO, José Luís. Considerações teórico-metodológicas sobre as formas de organização do espaço e suas tendências na América Latina. Planejamento, Salvador, v. 1, n.7, p.45-78, jan./mar. 1979.

CORRÊA, Roberto Lobato. Territorialidade e corporação: um exemplo. In: SANTOS, M., SOUZA, M.A.; SILVEIRA, M. L. (Org.). Território: globalização e fragmentação. São Paulo: Hucitec/Anpur, 1994.

. Espaço, um conceito-chave da Geografia. In: CORRÊA, Rogério Lobato (Org.).

Geografia, conceitos e temas. Rio de Janeiro: Bertrand Brasil, 2008. p.23-67.

COULON, Alan. Etnometodologia e Educação. Petrópolis: Vozes, 1995.

ELIAS, Norbert. O Processo civilizador. Rio de Janeiro: Zahar, 1990. v. 1, 2.

. A Sociedade da Corte. Rio de Janeiro: Zahar, 2001.

ELIAS, Norbert; SCOTSON, John. L. Os estabelecidos e os outsiders: sociologia das relações de poder a partir de uma comunidade. Rio de Janeiro: Jorge Zahar Editor, 2000. 
ESPÍNDOLA, Haruf Salmen. Sertão do Rio Doce. Bauru: EDUSC, 2005.

FAZENDA, Ivani Catarina Arantes. Integração e Interdisciplinaridade no Ensino Brasileiro. São Paulo: Edições Loyola, 2006.

GEERTZ, Clifford. A interpretação das culturas. Rio de Janeiro: Zahar, 1989.

GENOVEZ, Patrícia Falco; VILARINO, Maria Terezinha B. Entre práticas sanitárias e saberes tradicionais: a territorialização do saneamento no Médio Rio Doce. In: ESPINDOLA, H. S.; ABREU, J. L. (Org.). Território, Sociedade e modernidade em Governador Valadares. Governador Valadares: Ed. Univale, 2010.

GOMES, Rita de Cássia da Conceição. O conceito de território na trajetória do pensamento geográfico. Revista Sociedade e Território, Natal, v. 1, n. 1, Jan/Jun. 2004.

GUNTHER, Helmut. Pesquisa Qualitativa versus Pesquisa Quantitativa: essa é a questão? Revista Psicologia: Teoria e Pesquisa, Brasília, v. 22, n. 2, maio/ago., 2006.

HASESBAERT, Rogério. Identidades Territoriais. In: CORRÊA, Roberto Lobato; ROSENDAHL, Zeny (Org.) Manifestações da cultura no Espaço. Rio de Janeiro: EdUERJ, 1999.

.O mito da desterritorialização: do "fim dos territórios" à multiterritorialidade. Rio de Janeiro: Bertrand Brasil, 2004.

Desterritorialização: entre redes e os aglomerados de exclusão. In: CORRÊA, Roberto Lobato: Geografia Conceitos e temas. Rio de Janeiro: Bertrand Brasil, 2008.

HERITAGE, John C. Etnometodologia. In: GIDDENS, Anthony; TURNER, Jonathan (orgs.). Teoria Social Hoje. São Paulo: UNESP, 1999. p.12-32.

HOLZER, Werther. A geografia humanista: sua trajetória de 1950 a 1990. Rio de Janeiro: RJ/PPGG, 1992.

IBGE. Diretoria Técnica. Geografia do Brasil. Região Sudeste. Rio de Janeiro: SERGRAF-IBGE, 2010.

ISNARD, Hildebert. O Espaço Geográfico. Coimbra: Almedina, 1982.

KOGA. Dirce. Medidas de cidades: entre territórios de vida e territórios vividos. São Paulo: Cortez, 2003.

MARQUES, Francisca Ester Sá. Interpretação de produtos culturais: contributos de uma abordagem etnometodológica aos estudos de comunicação. São Luís: UFMA, 2005.

MELLO, Luiz Gonzaga de. Antropologia Cultural: iniciação, teoria e temas. Petrópolis: Vozes, 2009.

SAQUET, Marcos. Os tempos e os territórios da colonização italiana. Porto Alegre: EST Edições, 2003.

SILVA, Joseli Maria. Cultura e territorialidades urbanas: uma abordagem da pequena cidade. Rio de Janeiro: UFRJ, 2006. 
SIMAN, Lana Mara de Castro. A História na Memória: uma contribuição para o ensino de história de cidades. 1988. Dissertação (Mestrado em Educação) - Faculdade de Educação, UFMG, Belo Horizonte, 1988.

SIQUEIRA, Sueli. O trabalho e a pesquisa científica na construção do conhecimento. Governador Valadares: Universidade do Vale do Rio Doce, 2005.

TUAN, Yi-Fu. Espaço e lugar: a perspectiva da experiência. São Paulo: DIFEL, 1983.

VILARINO, Maria Terezinha B. Entre lagoas e florestas: atuação do Serviço Especial de Saúde Pública (SESP) no saneamento do Médio Rio Doce (1942 e 1960). Dissertação (Mestrado em Educação) - Faculdade de Educação, Belo Horizonte, UFMG, 2008.

WEBER, Max. A Ética Protestante e o espírito do Capitalismo. São Paulo: Pioneira, 1996.

_ _ _ _ _. Sobre a teoria das ciências sociais. São Paulo: Moraes, 1991.

_. _ _ _.. Metodologia das Ciências Sociais. São Paulo: Cortez, UNICAMP, 1992.

WILLIAMS, Raymond. Cultura e Sociedade. São Paulo: Nacional, 1969. 